\title{
Recurrent syncope: a slow heart rate?
}

\author{
M. Boulaksil • D. Robbers-Visser $\cdot$ S. Westra $\cdot$ \\ J. L. Smeets
}

Published online: 14 July 2013

(C) The Author(s) 2013. This article is published with open access at Springerlink.com

A 70-year-old female patient was admitted to the geriatrics department with an overall deterioration, including lethargy, and with recurrent syncope. She had no palpitations or chest pain or other symptoms preceding the syncopal episodes. She is known with a history of an anterior myocardial infarction more than 20 years ago and psychotic depression. Her current medication consisted of lithium $400 \mathrm{mg}$, olanzapine $10 \mathrm{mg}$ and nortriptyline $50 \mathrm{mg}$, all once a day, along with cardiac medication. Physical examination, initial laboratory tests and echocardiography did not demonstrate any abnormalities.

A 12-lead surface electrocardiogram on admission is shown in Fig. 1. What is your diagnosis?

\section{Answer}

You will find the answer elsewhere in this issue.

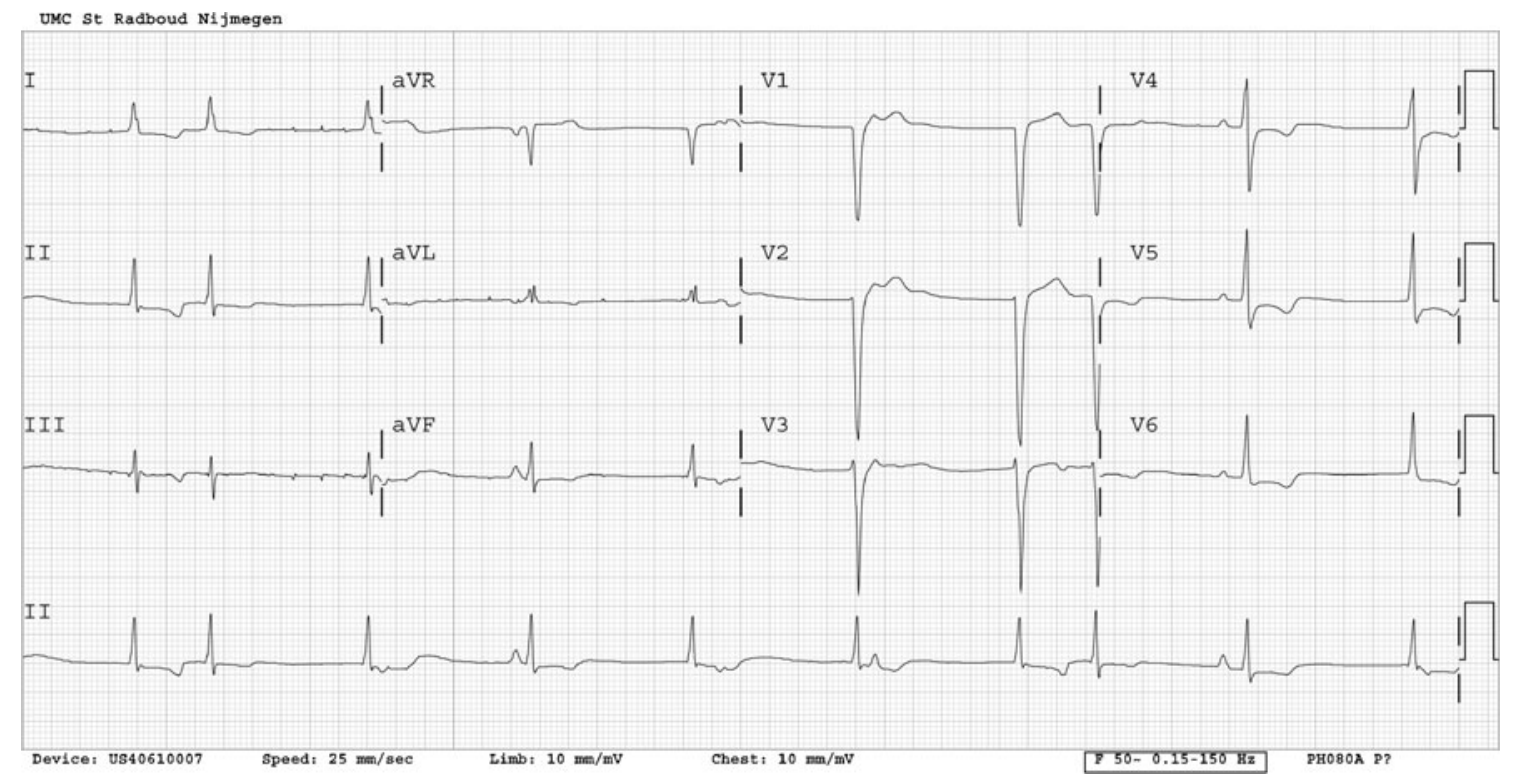

Fig. 1 Twelve-lead surface electrocardiogram on admission

M. Boulaksil $(\bowtie) \cdot$ D. Robbers-Visser $\cdot$ S. Westra $\cdot$ J. L. Smeets Department of Cardiology 670, Radboud University Nijmegen Medical Centre, PO Box 9101, 6500 HB Nijmegen, the Netherlands e-mail:m.boulaksil@gmail.com
Open Access This article is distributed under the terms of the Creative Commons Attribution License which permits any use, distribution, and reproduction in any medium, provided the original author(s) and the source are credited. 